\title{
WHY PATIENTS SHOULD BE INVOLVED IN HEALTH TECHNOLOGY ASSESSMENT
}

Janet Wale

Health Technology Assessment International (HTAi) Patient and Citizen Involvement in HTA Interest Group

socrates171@bigpond.com

Anna Mae Scott

Centre for Research in Evidence-Based Practice

Biørn Hofmann

Department for Health Sciences, Norwegian University of Science and Technology; Centre for Medical Ethics, University of Oslo

\author{
Sarah Garner \\ National Institute for Health and Care Excellence \\ Eric Low \\ Myeloma UK \\ Lloyd Sansom \\ Division of Health Sciences, University of South Australia
}

Objectives: Some countries make considerable effort to involve patients and patient groups in their health technology assessment (HTA) processes; others are only just considering or are yet to consider patient involvement in HTA.

Methods: This commentary offers four arguments why patient involvement should be prioritized by those HTA agencies that do not yet involve patients: (1) from a patients' rights perspective, (2) based on patient and community values, (3) centering on evidentiary contributions, and (4) from a methodological perspective.

Results: The first argument builds on the Alma-Ata Declaration, which holds that patients have a right and duty to have a say in the planning and delivery of their health care, individually and collectively. Where HTA is used to determine access to technologies and services, we argue that patients have a right to be heard. The second argues that decisions about treatments and services need to be aligned with the core values and morals of the patients whom the health system serves. The third argues that patients have unique knowledge and insights about living with a health condition and their needs for services and treatments regarding that condition, which can add to the knowledge base and value of the HTA process. The fourth argues that involvement of patients can facilitate methodological advancement of HTA, in areas such as early scientific advice and managed entry with evidence development.

Conclusions: An HTA process that includes patient perspectives can, therefore, provide added value to patients, policy makers and healthcare professionals alike.

Keywords: Health technology assessment, Patient involvement, Patient values, Decision making, Patient experience, Patient perspectives

Health technology assessment (HTA) is applied within the societal context of health care. Its methodologies are designed to ensure internal scientific validity and provide accountability, yet assessing value to patients in terms of acceptability of the technology, applicability within the everyday practice of health care, immediate and longer term outcomes, and social consequences is also important (1). The HTAi Patient and Citizen Involvement in HTA Interest Group glossary defines HTA as the systematic evaluation of the clinical effectiveness, cost-effectiveness, and social and ethical impact of a health technology on the lives of patients and the healthcare system

This commentary was developed as a result of participation (J.W.) in Policy Forum panel sessions at the Health Technology Assessment International (HTAi) 2013 and 2014 Annual Meetings, to present the patient perspective; and the organization of a Patient and Citizen Involvement in HTA Interest Group workshop (2014) on "A critical perspective on quality of life and qualitative studies in relation to patients' experiences in HTA". The HTAi Policy Forum brings together leaders and senior management of for-profit and not-for-profit organizations with strategic interests in HTA and presents a panel session at each annual meeting. Open discussion is an important component of HTAi, its Policy Forum, and Interest Groups. Undertaking this task was possible through the encouragement of the co-authors. This work is unfunded. Thank you to the peer reviewers for comments that strengthened this publication.
(Glossary) (2). More traditional definitions do not refer specifically to patients but include social and ethical aspects (3). How and whether patients are involved in HTA is generally dependent on health policy decisions of a particular country, and the mechanisms to involve patients have changed only incrementally over the years $(4 ; 5)$. This is despite reports that HTA can be strengthened by inclusion of the patient perspective and committing resources to supporting patient participation (6-8).

Some countries already make substantial efforts to integrate patient involvement into their HTA processes. These include: the National Institute for Health and Care Excellence (NICE) in England (9), the Scottish Medicines Consortium in Scotland (10), the Canadian Agency for Drugs and Technologies in Health (CADTH) (11), and the pan-Canadian Oncology Drug Review (12). However, other countries are only just starting to consider or are yet to consider public involvement (13). Although some HTA organizations provide reasons why patients are involved, the stated purpose of such involvement may not always be clear $(8 ; 14 ; 15)$.

In this commentary, we have consolidated key arguments why patients should be involved in HTA to aid discussion and future developments. We set out to provide arguments why 
patients should play a robust part in HTA, not just in some countries but as a broad principle of HTA. The arguments we present are not limited to the Western context, and should, therefore, also appeal to HTA agencies situated in non-Western countries, paving the way for broader uptake.

\section{FOUR ARGUMENTS IN FAVOR OF PATIENT INVOLVEMENT IN HTA}

\section{Argument from a Patients' Rights Perspective}

The Alma-Ata Declaration in 1978 reaffirmed that health, with its physical, mental, and social aspects, is a fundamental human right; and that people have the right and duty to participate individually and collectively in the planning and delivery of their health care (16). The Declaration describes primary health care as essential health care based on practical, scientifically sound, and socially acceptable methods and technology at a cost that the community and country can afford to maintain. The World Health Organization adopted this challenge, and in May 2014 went on to approve a resolution on health intervention and technology assessment in support of universal health coverage (17).

As patients have a right to participate in the planning and delivery of their health care, and the HTA process typically determines the health services and procedures available to patients, it follows that patients have a right to be heard as part of the HTA process. Such patient involvement can take many forms, including providing submissions, generally through patient groups, detailing experiences with a particular health condition or health technology (8), as expert patients or providing patient stories or interviews (18), and as patient representatives on an HTA committee (12). In engaging patients in these ways, HTA agencies can enable patients to be part of the policy level decision making for which healthcare technologies are available. Beyond respecting patients' rights, such engagement has the added value of building public trust in the health system processes and in increasing transparency (19).

\section{Argument Based on Values}

The determination of the cost-effectiveness of an intervention is an important factor in the final recommendations of an HTA committee in countries that include it in their HTA processes and can predominate over other considerations that underpin a healthcare system (20). However, value determinations and value judgements are also needed as part of HTA decision making $(21 ; 22)$. This is because value judgements underpin which health technologies and treatments are, and are not, assessed; what comparators are selected; and which populations are considered eligible to access a treatment or procedure (21). The benefits of a technology and, therefore, its value to patients in terms of health outcomes are also dependent not just on the technology but how it is used, the effectiveness of other interventions throughout the care pathway, and interaction with multiple healthcare providers (11).
Moreover, due to cultural and belief system differences across countries, each country has its own values that underlie its health system and HTA processes. Therefore, patient and community values should be taken into account in the evaluation of health technologies so that the HTA decisions reflect the value to patients and the community. Involving patients and the public in the HTA processes is an important way to identify and integrate these values.

The NICE Citizens Council in the United Kingdom is an exemplar methodology for eliciting community values, as demonstrated by its determination of the values that need to be considered when making decisions about trade-offs between equity and efficiency (23). Although "patient values" and "citizen values" may differ, the Citizens Council is inclusive of those with health issues and includes a cross-section of the community. The Citizens Council uses deliberative methods to develop a consensus view of values, where the perspectives of subsets of the community may have widely differed at the beginning of the deliberations. This helps to ensure that decisions about treatments and services that are funded by the National Health Service are aligned with the core values and morals of those whom the health system serves.

\section{Argument Centering on Evidentiary Contributions}

HTA decisions are informed by scientific evidence in the form of clinical trials. However, clinical research alone often does not provide complete information about patient outcomes and the total costs of care (1). For example, the elements of benefit to the patient may not be captured in the measure of health gain, or they may be broader than the health outcomes assessed in the trial (21). Patient-relevant outcomes may also not be clearly reflected in quality of life data (24).

However, patients can provide valuable insights to inform the HTA decision-making process. These insights include: how it is to live with the condition, what it is like to be treated for that condition within the health system, what their unmet needs are, and other information that is not obtainable from clinical trials or medical practitioners. Thus patients or carers can express the value to them of a drug treatment to reduce the need for repeated surgery in young children; a different class of drugs with potentially reduced side effects, where all existing drugs were of the same class and had serious toxicities; availability of a medical procedure that allows withdrawal of poorly effective medications to control heart rhythm; and the experiences of living with cardiac devices such as implanted defibrillators. Such insights can provide valuable context and understanding of the health technology under assessment that are not captured, or perhaps even capturable, within clinical trials (25).

Work in this area has already begun. Patients are keen to be heard in health care, research, and policy decision making by providing input; capacity exists for the robustness of that input to be considerably strengthened (26). In one example, 
researchers partnered with a patient advisory board whose members were able to identify that their active presence at focus groups of patients added value to the researcher-led focus groups by instilling trust and confidence of the participants (27). Qualitative research methodologies exist and can be used to provide important knowledge based on a range of patient perspectives $(7 ; 28)$, and provide a depth of understanding of issues related to illness and the appropriateness and acceptability of interventions (29). Additionally, measurement of the stated preferences of patients in terms of outcomes of healthcare interventions is another research methodology being developed to bring a patient perspective to HTA (15).

\section{Argument from a Methodological Perspective}

HTA methodologies are not static but continue to evolve, and patients can be an important part of that evolution. Two new advances to meet the demands currently being made for timely HTA are: early scientific advice, and managed entry into the health system together with the accrual of real-world evidence. Patients have a role to play in each of these. Early scientific advice is offered by some HTA agencies. CADTH, for example, interviews patients to help inform that advice, and to identify patients' needs (30). In addition, patients can give advice on study design, to maximize recruitment and retention of participants, address patient relevant endpoints, and ensure that quality of life is measured as an outcome (31).

Patient input into data collection is also important. This may be in the form of patient-reported outcomes for clinical studies, where digital collection methods and large datasets are part of the changing paradigm (32). Finally, where evidential uncertainties remain when undertaking an HTA of an innovative health technology a managed entry pathway may be considered, to allow the collection of real-world evidence (e.g., through a registry) while providing early access to a health technology. The goals and benefits of using this pathway need to be weighed up against the potential risks for patients, the need for truly informed consent, and patient participation in data collection (32).

\section{CONCLUSION}

Countries such as Scotland, England, and Canada make a considerable effort to integrate patient perspectives into their HTA systems, and continue to develop their processes for patient involvement. Other countries have yet to develop this aspect of their HTA processes. We offer here key arguments for why patient perspectives should be part of HTA in those countries, centering on: patient rights, alignment with patient and community values, evidentiary contributions, and a methodological development perspective.

By refraining from listing specific patient values, or delineating how patient perspectives are to be obtained, our intent is that these arguments are universally applicable, that is, they can appeal to agencies situated in both Western and non-Western countries. Methodologies and approaches for person-centered HTA and inclusion of patient perspectives are still in development. Therefore, recognition of the importance of including patient perspectives and implementation internationally is a key first step toward continued advancement.

\section{CONFLICTS OF INTEREST}

Dr. Wale reports that she is an immediate past chair of the HTAi Interest Group on Patient and Citizen Involvement in HTA (PCIG). Dr. Scott reports that she is a member of HTAi's Interest Group on Patient and Citizen Involvement in HTA (PCIG). Doctors Hofmann, Garner, Low and Sansom have nothing to disclose.

\section{REFERENCES}

1. Porter ME. What is value in health care? N Engl J Med. 2010;363:24772481.

2. HTAi Patient and Citizen Involvement in HTA Glossary. http://www. htai.org/fileadmin/HTAi_Files/ISG/PatientInvolvement/v2_files/ Resource/PCISG-Resource-ENGLISH-PatientandConsumerGlossaryOct09.pdf (accessed June 10, 2016).

3. Banta D. What is technology assessment? Int J Technol Assess Health Care. 2009;25:7-9.

4. Gauvin F-P, Abelson J, Giacomini M, Eyles J, Lavis JN. Moving cautiously: Public involvement and the health technology assessment community. Int J Technol Assess Health Care. 2011;27:43-49.

5. Wortley S, Wale J, Grainger D, Murphy P. Moving beyond the rhetoric of patient input in health technology assessment deliberations. Aust Health Rev. 2016. May 26. doi:10.1071/AH15216. [Epub ahead of print].

6. Facey K, Boivin A, Gracia J, et al. Patients' perspectives in health technology assessment: A route to robust evidence and fair deliberation. Int J Technol Assess Health Care. 2010;26:334-340.

7. Gagnon MP, Desmartis M, lepage-Savary D, et al. Introducing patients' and the public's perspectives to health technology assessment: A systematic review of international experiences. Int J Technol Assess Health Care. 2011;27:31-42.

8. Berglas S, Jutai L, MacKean G, Weeks L. Patients' perspectives can be integrated in health technology assessments: An exploratory analysis of CADTH Common Drug Review. Research Involvement and Engagement. 2016;2:21.

9. The National Institute for Health and Care Excellence (NICE). http://www.nice.org.uk/about/nice-communities/public-involvement (accessed June 7, 2016).

10. Scottish Medicines Consortium. https://www.scottishmedicines.org.uk/ Public_Involvement (accessed June 7, 2016).

11. Canadian Agency for Drugs and Technologies in Health (CADTH). https://www.cadth.ca/about-cadth/what-we-do/products-services/cdr/ patient-input) (accessed June 7, 2016).

12. pan-Canadian Oncology Drug Review. https://www.cadth.ca/pcodr/ patient-input-and-feedback (accessed June 7, 2016).

13. Hailey D, Werkö S, Bakri R, et al. Involvement of consumers in health technology assessment activities by INAHTA agencies. Int J Technol Assess Health Care. 2013;29:79-83.

14. Kreis J, Schmidt H. Public engagement in health technology assessment and coverage decisions: A study of experiences in France, Germany, and the United Kingdom. J Health Polit Policy Law. 2013;38:89-122. doi:10.1215/03616878-1898812. 
15. Dirksen CD. The use of research evidence on patient preferences in health care decision-making: Issues, controversies and moving forward. Expert Rev Pharmacoeconom Outcomes Res. 2014;14:785-794.

16. World Health Organization. Declaration of Alma-Ata 1978. http://who. int/publications/almaata_declaration_en.pdf (accessed June 7, 2016).

17. Sixty-seventh World Health Assembly WHA67.23 Agenda item 15.7, 24 May 2014. Health intervention and technology assessment in support of universal health coverage. http://apps.who.int/gb/ebwha/pdf_ files/WHA67/A67_R23-en.pdf (accessed June 7, 2016).

18. Staley K, Doherty C. It's not evidence, it's insight: Bringing patients' perspectives into health technology appraisal at NICE. Research Involvement and Engagement. 2016;2:4.

19. Drummond M, Tarricone R, Torbica A. Assessing the added value of health technologies: Reconciling different perspectives. Value Health. 2013;16:S7-13.

20. Towse A, Barnsley P. Approaches to identifying, measuring, and aggregating elements of value. Int J Technol Assess Health Care. 2013;29:360-364.

21. Hofmann B, Cleemput I, Bond K, et al. Revealing and acknowledging value judgments in health technology assessment. Int $J$ Technol Assess Health Care. 2014;3:579-586.

22. Henshall C, Schuller T; HTAi Policy Forum. Health technology assessment, value-based decision making, and innovation. Int J Technol Assess Health Care. 2013;29:353-359.

23. NICE Citizens Council Meeting Report 8-9 May 2014. What are the societal values that need to be considered when making decisions about trade-offs between equity and efficiency? http://www.nice.org.uk/Media/ Default/Get-involved/Citizens-Council/Reports/cc-report17-equityefficiency.pdf (accessed June 10, 2016).
24. Kinter ET, Schmeding A, Rudolph I, dosReis S, Bridges JF. Identifying patient-relevant endpoints among individuals with schizophrenia: An application of patient-centered health technology assessment. Int J Technol Assess Health Care. 2009;25:35-41.

25. Greenhalgh T, Snow R, Ryan S, Rees S, Salisbury H. Six 'biases' against patients and carers in evidence-based medicine. BMC Med. 2015;13:200. doi:10.1186/s12916-015-0437-x.

26. Anderson M, McCleary KK. On the path to a science of patient input. Sci Transl Med. 2016;8:336ps11.

27. Johnson DS, Bush MT, Brandzel S, Wernli KJ. The patient voice in research - Evolution of a role. Research Involvement and Education. 2016;2:6.

28. Hansen HP, Draborg E, Kristensen FB. Exploring qualitative research syntheses: The role of patients' perspectives in health policy design and decision-making. Patient. 2011;4:143-152.

29. Tjørnhøj-Thomsen T, Ploug Hansen H. Knowledge in health technology assessment: Who, what, how? Int J Technol Assess Health Care. 2011;27:324-329.

30. CADTH. Patient involvement in scientific advice. https://www.cadth.ca/ scientific-advice/patient-involvement (accessed June 10, 2016).

31. Low E. Potential for patients and patient-driven organizations to improve evidence for health technology assessment. Int J Technol Assess Health Care. 2015;31:226-227.

32. Basch E. New frontiers in patient-reported outcomes: Adverse event reporting, comparative effectiveness, and quality assessment. Annu Rev Med. 2014;65:307-317.

33. Husereau D, Henshall C, Jivraj J. Adaptive approaches to licensing, health technology assessment, and introduction of drugs and devices. Int J Technol Assess Health Care. 2014;30:1-9. 